\title{
Melhoria do acesso em uma Estratégia Saúde da Família em tempos de pandemia pela COVID-19: um relato de experiência
}

Improving access to a family health strategy in times of pandemic by COVID-19: an experience report

Mejora del acceso a una estrategia de salud familiar en tiempos de pandemia por el COVID-19: un informe sobre la experiencia

Geovane Menezes Lourenço ORCID: https://orcid.org/0000-0002-4242-8318 Universidade Federal do Paraná, Brasil E-mail: mangeo@ hotmail.com

Diego Osmar Rodrigues ORCID: https://orcid.org/0000-0001-8451-5439 Universidade Estadual de Ponta Grossa, Brasil E-mail: diegoosmar.rodrigues@hotmail.com

Kamila Silva Chenek ORCID: https://orcid.org/0000-0003-0535-1902 Universidade Estadual de Ponta Grossa, Brasil E-mail: kchenek@hotmail.com

Anne Karollyne de Lim ORCID: https://orcid.org/0000-0001-5903-748X Universidade Estadual de Ponta Grossa, Brasil E-mail: karollyedelima@ hotmail.com

Jackson Paiva Gustavson

ORCID: https://orcid.org/0000-0001-5398-6385 Universidade Estadual de Ponta Grossa, Brasil E-mail: jackson.gustavson@alumni.usp.br Anna Julia Zilli Lech

ORCID: https://orcid.org/0000-0003-2649-8313 Universidade Estadual de Ponta Grossa, Brasil E-mail: annajzlech@gmail.com

\begin{abstract}
Resumo
O objetivo do presente artigo é relatar a experiência das equipes de estratégia saúde da família (ESF) de uma unidade de saúde, quanto a reorganização do fluxo do atendimento com intuito de melhorar o acesso em tempos de pandemia devido ao COVID-19. Consiste em um estudo descritivo, no qual se buscou reorganização do fluxo e do atendimento, visando proporcionar o acesso integral às pessoas no serviço de saúde, diretamente ou indiretamente, evitar número de contágio e infecção por COVID-19 entre a população, diminuir o risco de contágio aos profissionais da unidade, evitar a propagação rápida do vírus. Percebe-se que o processo de organização do fluxo da unidade teve bons resultados como participação interprofissionais e adesão dos pacientes, a equipe conseguiu suprir as necessidades básicas dos pacientes, mantendo vínculo com os usuários priorizando as situações crônicas e descompensadas, bem como os cuidados preventivos com foco na promoção de saúde, enfatizando a prevenção da infecção pelo Sars-Cov 2.

Palavras-chave: Acesso; Educação em saúde; Sars-Cov 2; COVID-19.
\end{abstract}

\begin{abstract}
The objective of this article is to report the experience of the FHS teams of a health unit, regarding the reorganization of the flow of care in order to improve access in times of pandemic due to the COVID-19. It consists of a descriptive study, which sought to reorganize the flow and care, aiming to provide full access to people in the health service, directly or indirectly, avoiding the number of contagion and infection by COVID-19 among the population, reducing the risk of contagion to the professionals of the unit, avoid the rapid spread of the virus. It is noticed that the process of organizing the flow of the unit had good results, such as interprofessional participation and patient compliance, the team was able to meet the basic needs of patients, maintaining links with users prioritizing chronic and decompensated situations, as well as preventive care. focusing on health promotion, emphasizing the prevention of infection by Sars-Cov 2.
\end{abstract}

Keywords: Access; Health education; SARS-CoV-2; COVID-19. 


\section{Resumen}

El objetivo de este artículo es informar sobre la experiencia de los equipos de estrategia de salud familiar (ESF) de una unidad de salud, en lo que respecta a la reorganización del flujo de atención a fin de mejorar el acceso en tiempos de pandemia debido al OVID-19. Se trata de un estudio descriptivo en el que se reorganizó el flujo y la atención a fin de proporcionar pleno acceso a las personas del servicio de salud, directa o indirectamente, para evitar el número de contagios e infecciones por COVID-19 entre la población, reducir el riesgo de contagio a los profesionales de la unidad y evitar la rápida propagación del virus. Es notable que el proceso de organización del flujo de la unidad tuvo buenos resultados, como la participación interprofesional y el cumplimiento de los pacientes, el equipo fue capaz de satisfacer las necesidades básicas de los pacientes, manteniendo los vínculos con los usuarios al dar prioridad a las situaciones crónicas y descompensadas, así como la atención preventiva centrada en la promoción de la salud, haciendo hincapié en la prevención de la infección por Sars-Cov 2.

Palabras clave: Acceso; Educación para la salud; Sars-Cov 2; COVID-19.

\section{Introdução}

\subsection{Conceito e transmissão coronavírus}

A transmissão da Sars-Cov-2, iniciou em dezembro de 2019, em Wuhan, na provínciade Hubei na China, sendo declarada em 11 de março de 2020 pandemia, pela Organização Mundial da Saúde (OMS) ocorrência global de casos da doença nomeada COVID-19 (World Health Oganization, 2020). No Brasil, a divulgação do primeiro caso confirmado foi em 26 de fevereiro de 2020 (Brasil, 2020a). Desde então, houve um crescimento exponencial do número de infectados no país (Amorim et al., 2020), dentre os quais, casos sintomáticos com apresentação de uma pneumonia atípica e/ou com Síndrome Respiratória Aguda Grave (SRAG) (Brasil, 2020b).

A partir disso, a OMS passou a divulgar medidas a serem adotadas para o enfrentamento e prevenção da disseminação da COVID-19 (Mercês et al., 2020). Sendo elas: Isolamento social, higienização das mãos, uso de máscaras, distanciamento social, espaços separados para triagens à pacientes com suspeita de caso respiratório, capacitação da equipe de saúde para o manejo do paciente, como e quando utilizar os equipamentos de proteção individual e reforço da higienização do ambiente (Agência Nacional de Vigilância Sanitária, 2018; 2020; Oliveira et al., 2020).

Dessa forma, a Unidade Básica de Saúde (ESF) sofreu mudanças na organização do fluxo e do processo de trabalho, com o intuito de minimizar a transmissão da infecção por COVID-19 (Carvalho et al., 2020).

Neste contexto, surgiu a seguinte problemática: como está organizado o fluxo do atendimento em situações de pandemia na unidade de saúde? Diante dessa problemática sentiu-se a necessidade de reorganização do fluxo e do atendimento, visando proporcionar o acesso integral às pessoas no serviço de saúde, diretamente ou indiretamente por meio da visita domiciliar do ACS.

Starfield (2002) descreve o acesso como um atributo essencial na Atenção Primária, o qual permite o primeiro contato do indivíduo à Unidade de Saúde, contemplando o atendimento pela integralidade, longitudinalidade e coordenação da atenção, e suas derivações permitem a atenção centrada na família, na comunidade, levando em consideração a competência cultural para facilitar a relação entre profissional e usuário.

Uma das principais práticas de sensibilização é a higienização das mãos, sendo reconhecida como uma técnica de prevenção e controle a infecções relacionadas a assistência à saúde, principalmente pela permanência prolongada do Sars-cov 2 ao ambiente Agência (Nacional de Vigilância Sanitária, 2018; 2020).

Visando que a APS é considerada a porta de entrada sendo a ordenadora e coordenadora do cuidado, neste contexto foi necessário reorganização do processo de trabalho para facilitar o acesso e atendimento integral individual e coletivo, bem como, a promoção e prevenção por meio do vínculo, tendo enfoque as orientações relacionadas educação na saúde para as pessoas que compareciam até a unidade com intuito de sensibilizar a população local com relação às medidas preventivas contra a COVID-19. 


\section{Metodologia}

Este estudo tem uma natureza qualitativa e consiste em um relato de experiência (Pereira et al., 2018), para o qual utilizou-se o recurso metodológico da narrativa para relatar vivências dos residentes multiprofissionais em saúde das áreas: enfermagem, odontologia, veterinária, educação física, e um enfermeiro e seu preceptor, com início em 25 de março de 2020 até 20 de julho de 2020 em uma unidade de saúde no município de Ponta Grossa, PR. A unidade de saúde está composta por duas equipes com um médico, dois enfermeiros, dois técnicos de enfermagem, 7 agentes comunitárias e 4 residentes, consta também com uma equipe de odontologia, um zelador e dois administrativos, possui uma população de 8.900 pessoas aproximadas, e um total de 2428 famílias. A atuação dos residentes é regulamentada pela Lei Federal n 11.129 de 2005 como modalidade de ensino de pós-graduação lato sensu, que atua junto a equipe em manejo ao paciente, como linha de frente e combate ao SarCov-2 (Ossege, 2020).

Diante disso a reorganização do fluxo de atendimento teve o intuito de melhorar o acesso em tempos de pandemia pelo COVID-19, no qual se buscou discutir com a equipe novas formas de priorizar o atendimento no serviço de saúde. Este relato foi estruturado em quatro momentos: o primeiro se refere a uma breve caracterização da AB na cidade de Ponta Grossa; o segundo narra o caminho percorrido pelos profissionais durante o planejamento do fluxo; o terceiro descreve a operacionalização; e o quarto descreve as reflexões geradas após vivência dessa experiência pelos profissionais de saúde no contexto em tempos de pandemia.

Ficou preconizado que na unidade seriam realizadas as consultas de pré-natais, urgências e os sintomáticos respiratórios.

\section{Resultados e Discussão}

Foi organizado o fluxo da unidade, bem como, o processo de trabalho com intuito de permitir o acesso diretamente ou indiretamente aos pacientes do território, percebeu-se que os objetivos propostos foram alçados, com redução do fluxo interno e externo a unidade, bem como a organização da fila com distanciamento, no intuito de sensibilizar os pacientes aos cuidados de prevenção, foram intensificadas conversa com os pacientes na fila promovendo educação em saúde pela equipe e residência multiprofissional.

Os pacientes que chegavam à unidade eram recebidos na porta e direcionados conforme suas necessidades. Os sintomáticos respiratórios eram acolhidos, recebiam máscara e faziam desinfecção das mãos com álcool 70\%, após encaminhados para uma sala específica (isolamento), recebendo atendimento integral da equipe de enfermagem e médica.

Caso o paciente fosse diagnosticado com síndrome respiratória suspeito de COVID-19, o mesmo era notificado e recebia orientações para se mantiver em isolamento respiratório no domicílio por 14 dias, e posteriormente monitorado pela equipe da unidade de saúde (Brasil, 2020c). Sendo assim, pacientes em grupo de risco eram acompanhados a cada 24 horas e os não pertencentes a cada 48 horas.

Gestantes e crônicos com alguma descompensação permaneceram com agendamento de consultas, sendo ela delimitada à atendimentos de 30 em 30 minutos, permanecendo em sala de espera no máximo 3 a 4 pessoas, respeitando o distanciamento, visando que a recepção mede aproximadamente 30 metros quadrados. As demais procuras como queixa de infeção urinária, dores agudas sempre tiveram atendimento de forma holístico pela enfermagem e médico.

As Agentes Comunitárias em Saúde (ACS), tiveram um papel de extrema importância, mantiveram o elo entre unidade e comunidade, os quais orientavam e traziam as necessidades para combate aos agravos à saúde da população.

Esse contato se deu através das visitas domiciliares, porém devido ao contexto vivido, mudanças foram estabelecidas para garantir a segurança do profissional e paciente. Medidas socioeducativas, distanciamento e prevenção foram consolidadas, 
e os pacientes crônicos foram assistidos com qualidade através do acompanhamento e verificação de receitas e/ou entrega de medicamentos, tendo boa aderência dos usuários e suas necessidades (Brasil, 2020d).

Quanto à limpeza da unidade ficou estabelecido que a zeladora realizasse a desinfecção do chão e paredes duas vezes ao dia e a desinfecção das bancadas e das fechaduras com álcool 70\%. Além disso, foi determinado que cada profissional de saúde (seja enfermeiro, técnico de enfermagem, médico, entre outros) deveriam realizar a desinfecção com álcool $70 \% \mathrm{em}$ bancadas, superfícies e equipamentos utilizados após cada atendimento ou a cada duas horas como preconizados pelo Ministério da Saúde.

Onde estudos mostraram que o vírus pode permanecer em superfície até nove dias e quando realizado procedimentos que produzem aerossol por até 9 horas em ambiente suspenso, evidenciando a necessidade de uma desinfecção constante (Soeiro et al., 2020).

As atividades educativas também foram realizadas em forma de conversa e informativos, com os usuários que vinham até a unidade no período da manhã, os quais eram orientados quanto a importância de ficar em casa, distanciamento social, uso correto de máscara, bem como a higiene adequada das mãos.

Já as conversas fora efetuado em meio à dinâmicas de higiene correta das mãos, e na parte externa da unidade realizará demarcações para o distanciamento correto dos usuários.

Também se adotou medidas educativas com a equipe, estimulando a mudança de hábito e reforço às rotinas de higienização das mãos da equipe de saúde.

Foram realizadas dinâmicas em pequenos grupos (de 6 a 10 participantes), tendo um voluntário que calçava as luvas de procedimento e era vendado, então o mediador colocava uma colher de tinta guache na mão do voluntário e solicitava que o mesmo fizesse a técnica de lavagem de mãos rotineira. Após, o participante retirava a venda e discutiram-se com a equipe quais foram os erros e acertos. A ausência da tinta em determinadas partes destacava em quais locais da mão a higienização não ocorrerá de forma adequada.

\section{Considerações Finais}

Percebe-se que o processo de organização do fluxo da unidade teve bons resultados como participação interprofissionais e adesão dos pacientes. A equipe conseguiu suprir as necessidades básicas dos pacientes, mantendo vínculo com os usuários priorizando as situações crônicas e descompensadas, bem como os cuidados preventivos com foco na infecção pelo Sars-Cov 2. Mais estudos são necessários para o aprofundamento da temática de melhoria do acesso à ESF enfatizando suas adaptações ao contexto da pandemia pela COVID-19

\section{Referências}

Agência Nacional de Vigilância Sanitária (ANVISA). (2018). Nota técnica nº1/2018 GVIMS/GGTES/ANVISA: orientações gerais para higiene das mãos em serviços de saúde. Brasília: Brasil. 16 p. file:///C:/Users/18218/Downloads/Orientaes_para_HM_revisado_4.pdf

Agência Nacional de Vigilância Sanitária. (2020). Orientações para serviços de saúde: medidas de prevenção e controle que dev em ser adotadas durante a assistência aos casos suspeitos ou confirmados de infecção pelo novo coronavírus (SARS-CoV-2). (4a ed.), Brasília: Brasil. 92 p. http://portal.anvisa.gov.br/documents/33852/271858/Nota+T\%C3\%A9cnica+n+04-2020+GVIMS-GGTES-ANVISA/ab598660-3de4-4f14-8e6fb9341c196b28

Amorim, A. C. de, et al. (2020). Existential territories and Public Health: before and after the pandemic. Research, Society and Development, 9(12), e42791211362. https://doi.org/10.33448/rsd-v9i12.11362

Brasil. Ministério da Saúde. (2020a). Brasil confirma primeiro caso da doença - Brasília. http://www.saude.gov.br/noticias/agencia-saude/46435-brasilconfirma-primeiro-caso-de-novo-coronavirus

Brasil. Ministério da Saúde. (2020b). Painel de Casos de doença pelo novo coronavírus 2019 (COVID-19) no Brasil pelo Ministério da Saúde. https://covid.saude.gov.br 
Research, Society and Development, v. 10, n. 1, e36910111880, 2021 (CC BY 4.0) | ISSN 2525-3409 | DOI: http://dx.doi.org/10.33448/rsd-v10i1.11880

Brasil. (2020c). Protocolo de manejo clínico do coronavírus (COVID-19), na Atenção Primária à Saúde. (9a ed.), Brasília: Ministério da Saúde. 41 p. http://189.28.128.100/dab/docs/portaldab/documentos/20200504_ProtocoloManejo_ver09.pdf

Brasil. (2020d). Recomendações para adequação das ações dos agentes comunitários de saúde frente à atual situação epidemiológica referente ao COVID-19. (2a. ed.), Brasília: Ministério da Saúde. 10 p. https://www.conasems.org.br/wp-content/uploads/2020/04/20200403_recomendacoe s_ACS_COVID19_ver002_final_b.pdf

Carvalho, L. de S. et al. (2020). The impact of social isolation on people's lives during the COVID-19 pandemic period. Research, Society and Development, 9(7), e998975273. https://doi.org/10.33448/rsd-v9i7.5273

Mercês, D. M. et al. (2020). Coronavirus disease 2019 (covid-19): mechanisms, differential diagnosis and influence of intervention measures. Research, Society and Development, 9(8), e921986075. https://doi.org/10.33448/rsd-v9i8.6075

Pereira, A. S. et al. (2018). Metodologia da pesquisa científica. UAB/NTE/UFSM. https://repositorio.ufsm.br/bitstream/handle/1/15824/Lic_C omputacao_Metodologia-Pesquisa-Cientifica.pdf?sequence $=1$

Oliveira, J. P. S. et al. (2020). Understanding of COVID-19 on aspects related to social distancing. Research, Society and Development, 9(10), e5739108983.

Ossege, L. C. et al. (2020). Atuação do profissional de saúde residente no enfrentamento da COVID-19: um relato de experiência da secretaria de estado de saúde do distrito federal. Cenas Educacio, 3, e8489.

Soeiro, R. E. et al. (2020). Atenção Primária à Saúde e a pandemia de COVID-19: reflexão para a prática. Interam J Med Health, 3. https://doi.org/10.31005/iajmh.v3i0.83

Starfield, B. (2002). Atenção Primária: equilíbrio entre necessidade de saúde, serviços e tecnologia. Brasília: UNESCO, Ministério da saúde. 726 p. https://www.nescon.medicina.ufmg.br/biblioteca/imagem/0253.pdf

World Health Oganization (WHO). (2020). Metal health and psychosocial considerations during the COVID-19 outbreak. https://apps.who.int/iris/handle/10665/331490 